msh-mss Mathématiques et sciences humaines

182 | Été 2008

Varia

\title{
In memoriam : Georges-Théodule Guilbaud
}

In memoriam Georges-Théodule Guilbaud

\section{Marc Barbut}

\section{OpenEdition}

\section{Journals}

Édition électronique

URL : http://journals.openedition.org/msh/10612

DOI : $10.4000 / \mathrm{msh} .10612$

ISSN : 1950-682

\section{Éditeur}

Centre d'analyse et de mathématique sociales de l'EHESS

\section{Édition imprimée}

Date de publication : 30 juin 2008

Pagination : 5

ISSN : 0987-6936

\section{Référence électronique}

Marc Barbut, «In memoriam : Georges-Théodule Guilbaud », Mathématiques et sciences humaines [En ligne], 182 | Été 2008, mis en ligne le 11 juin 2008, consulté le 23 juillet 2020. URL : http:// journals.openedition.org/msh/10612 


\section{Georges-Théodule Guilbaud}

(1912-2008)

G.-Th. Guilbaud est mort le dimanche de Pâques 2008.

La création de notre revue fut décidée, en octobre 1962, lors de la séance de clôture d'un mémorable colloque qu'il avait organisé dans les locaux du Laboratoire d'anthropologie sociale, au Musée de l'Homme (Trocadéro). Bien entendu, les participants le choisirent par acclamation pour diriger la publication qui venait de naître.

Élu en 1955 directeur d'études (méthodes mathématiques des sciences sociales) à la $6^{\mathrm{e}}$ section de l'École pratique des hautes études, il y crée en 1960 et dirige jusqu'à sa retraite en 1981 le groupe de recherche devenu, après quelques avatars, l'actuel Centre d'analyse et de mathématique sociales.

De 1963 à 1996, il a publié dans la revue 28 articles (3 en collaboration), dont nombre de ceux qu'il jugeait les plus importants de sa production.

G.-Th. Guilbaud a joué un rôle considérable dans la diffusion et l'application des méthodes et techniques mathématiques, dans le monde des entreprises et des administrations de l'économie d'une part, dans celui de la recherche en lettres et sciences humaines d'autre part.

Mathématiques et Sciences humaines lui consacrera son prochain numéro.

Marc Barbut 